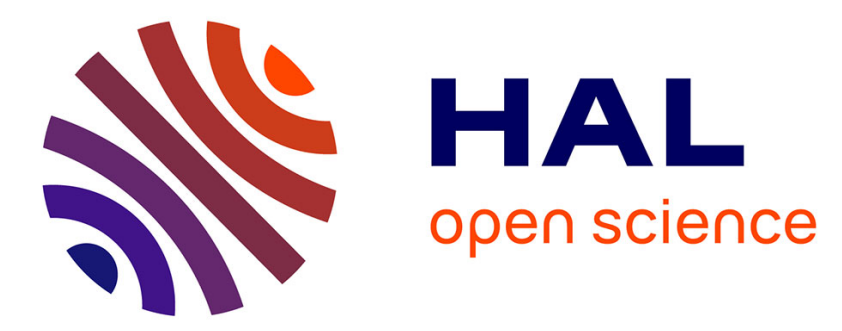

\title{
Coupled thermo-hydro-mechanical processes in fault zones during rapid slip \\ Jean Sulem
}

\section{To cite this version:}

Jean Sulem. Coupled thermo-hydro-mechanical processes in fault zones during rapid slip. Rock Mechanics in Civil and Environmental Engineering, EUROCK 2010, Jun 2010, Lausanne, Switzerland. pp.15-25. hal-00562457

\section{HAL Id: hal-00562457 https://hal.science/hal-00562457}

Submitted on 3 Feb 2011

HAL is a multi-disciplinary open access archive for the deposit and dissemination of scientific research documents, whether they are published or not. The documents may come from teaching and research institutions in France or abroad, or from public or private research centers.
L'archive ouverte pluridisciplinaire HAL, est destinée au dépôt et à la diffusion de documents scientifiques de niveau recherche, publiés ou non, émanant des établissements d'enseignement et de recherche français ou étrangers, des laboratoires publics ou privés. 


\title{
Coupled thermo-hydro-mechanical processes in fault zones during rapid slip
}

\author{
J. Sulem \\ CERMES - UR Navier, Ecole des Ponts Paris Tech, Université Paris-Est, France
}

Cite this paper as: J. Sulem: Coupled thermo-hydro-mechanical processes in fault zones during rapid slip, Keynote paper, Eurock 2010, Proceedings of the International Symposium of the International Society for Rock Mechanics, Lausanne, Switzerland, 15-18 June 2010, pp. 15-25.

\begin{abstract}
The physical processes which occur during an earthquake exhibit several coupled phenomena as large variations of stress, pore pressure and temperature take place in the slip zone. Thermo-poro-mechanical couplings due to shear heating can be associated to phase transition such as vaporization of the pore fluid, melting of fault gouge and to chemical effects such as dehydration of minerals or decarbonation of calcite. Different competing effects may influence dynamic slip and affect the weakening of the shear stress. In this paper, we show how thermal pressurization of the pore fluid and thermal decomposition of minerals induced by shear heating limit the co-seismic temperature rise which may explain the lack of pronounced heat outflow, and the lack of shallow frictional melting, along major tectonic faults.
\end{abstract}

\section{INTRODUCTION}

During the rupture of a fault, an earthquake occurs because the frictional resistance to slip on the fault walls decreases with increasing slip, causing an acceleration of sliding. To quantify the energy dissipated by an earthquake and assess the hazard of future ruptures, it is critical to understand the mechanics of slip weakening, i.e. how and how much fault friction drops in due course of the rupture.

The physical processes which occur during an earthquake exhibit many coupled phenomena as large variations of stress, pore pressure and temperature take place in the material. Thermo-poromechanical couplings due to shear heating (Rice 2006) can be associated to phase transition such as vaporization of the pore fluid at shallow depth (Sulem et al., 2007), melting of the rock at seismogenic depth (Boullier et al., 2001, Otsuki et al., 2003), and to chemical effects such as dehydration of minerals (Brantut et al. 2008, 2010) or decomposition of carbonates (Sulem and Famin, 2009). Different competing effects may counter balance one another depending on the kinetics of the various physical processes.

\section{MECHANISMS OF FAULT WEAKENING}

\subsection{Shear localization in faults}

Field observations of mature faults, i.e. faults that have experienced a large slip, show a generally broad zone of damaged rock, but nevertheless suggest that shear in individual earthquakes occur in very narrow localized zones of few millimeters thick or even less.
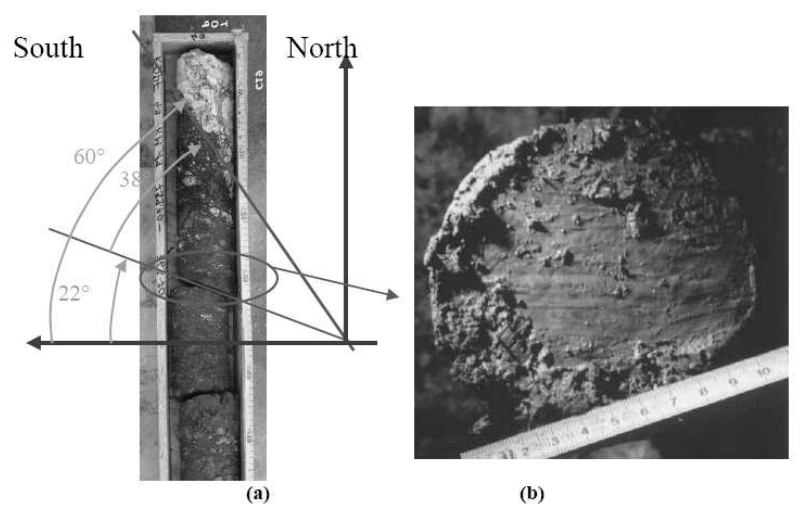

(b)

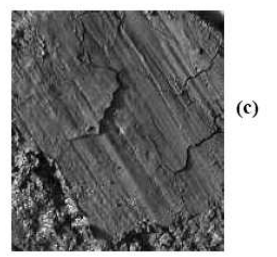

Figure 1. (a) The clayey core retrieved from Aigion fault (Greece); (b and c) Striation of the slip plane.

For example, during the drilling of Aigion Fault in the southern shore of the Gulf of Corinth, Greece, (Cornet et al, 2004a,b), the fault was intercepted at depth $760 \mathrm{~m}$, dipping at an angle of about $60^{\circ}$. The heart of the fault was found to be a $1 \mathrm{~m}$-thick band made of clay-rich material. Inside the clayey core, a clear shearing surface with marked slip lines is visi- 
ble on a plane that makes a $68^{\circ}$ angle with respect to the core axis (Sulem, 2007). This failure surface was not induced by the coring and extraction process but is indeed a slip plane as clear striation is observed at the interface (Fig. 1). Such an image clearly shows that the so-called failure plane is in reality a thin band of rapidly deforming material whereas the surrounding rock is moving, at least in the first stage of the process, as a rigid body. As the fault slip zones are very thin, thermal effects during rapid slip may be of primary importance. Fault zones exhibit commonly the presence of fluid interacting with the rock and thus coupled effects including shear heating, pore fluid pressurization, thermal mineral decomposition, should be taken into account in the understanding of fault weakening process.

\subsection{The heat flow paradox}

When an earthquake occurs, elastic strain energy is converted into radiated energy, i.e. the energy radiated by seismic waves, fracture energy, i.e. the energy associated with expanding the rupture area over the fault zone and frictional energy, i.e. energy required to overcome fault friction. It is generally estimated that more than $90 \%$ of the frictional work is converted into heat (Cocco et al, 2006).

Considering the extreme thinness of the slip zone $(<1-5 \mathrm{~mm})$ as mentioned above and assuming that the shear strength along a fault may be represented by a Coulomb friction law with friction coefficients of rocks relatively high $(\sim 0.6-0.85)$, one should observe measurable heat outflow near major faults and extensive melting along exhumed faults. However these effects are generally not found. The actual strength of San Andrea fault has been debated for more than 35 years because heat flow measurements did not show a narrow heat flow anomaly centered on the fault that would be expected from a conductive model of generated heat (Lachenbruch and Sass, 1988, Scholz, 2006). Two main lines of explanation, as summarized by Rice et al. (2009), have been explored to explain this paradox. The first one assumes that mature faults are weak either because the fault core material is different from the host rock and has a much lower friction coefficient due to the presence of clay or talc or because the pore pressure is high and nearly lithostatic. The other alternative is that major faults are statically strong but dynamically weaken during seismic slip. What physical process governs this dynamic weakening is still an open question.

\subsection{Dynamic weakening mechanisms}

As emphasized above, the slip zones are of extreme thinness and consequently it is expected that thermal weakening mechanisms are of major importance.

\subsubsection{Thermal weakening of the friction coefficient}

Flash heating and shear weakening of frictional micro-asperity contacts is a mechanism that has been first proposed for dry metal friction and recently applied to rock friction by Rice, 2006, Beeler et al, 2008, Noda et al. 2009. From the microscopic point of view, the contact between two rough surfaces is effective on micro-asperities with an area which is much smaller than the nominal contact area. The stresses supported by these asperities are much higher than the macroscopic applied stresses so that the local rate of heat production and consequently the local temperature rise during sliding is large and maybe sufficient to activate thermal weakening of the contacts.

Other mechanisms are related to the lubrication of the contact zone with the formation of silica gels ( $\mathrm{Di}$ Toro et al., 2004). This mechanism is only possible at large slip in wet silica-rich fault zones. The formation of a molten layer along the sliding interface also lubricates the contact zone and reduces the friction resistance. Field observations reveal the presence of veins of pseudotachylytes (solidified friction-induced melts) (e.g. Boullier et al., 2001, Otsuki et al., 2003, Di Toro et al. 2005, 2006). However, onset of macroscopic melting can only occur deep in the fault zone at seismogeneic depth and pseudotachylytes are relatively rare. Whether this scarcity of melt products is due to the fact that conditions for the onset of macroscopic melting do not generally occur or to the fact that they are not preserved is still an open debate. As discussed below, other mechanisms such as thermal pore fluid pressurization and thermal decomposition of minerals can limit the temperature rise and prevent melting to occur.

\subsubsection{Thermal pore fluid pressurization}

Fluid pressurisation under shear heating is a mechanism of thermal softening. The principle of slip weakening by thermal pressurization is based on the fact that pore fluids trapped inside the fault zone are put under pressure by shear heating, thus inducing a reduction of the effective mean stress, and of the shearing resistance of the fault plane (Lachenbruch, 1980, Mase and Smith, 1985, Rice, 2006, Sulem et al., 2005, 2007, Ghabezloo and Sulem, 2009). This mechanism has also been suggested for weakening in catastrophic landslides (Habib, 1967, 1975, Anderson, 1980, Voigt and Faust, 1982, Vardoulakis, 2002, Veveakis et al., 2007). The presence of clay material in fault zones also affects thermal pressurization as possible collapse of the clay under thermal loading may activate fluid pressurization (Sulem et al., 2004, 2005, 2007).

The values of the undrained thermal pressurization coefficient $\Lambda$, defined as the pore pressure increase due to a unit temperature increase in undrained condition, is largely dependent upon the nature of the material, the state of stress, the range of 
temperature change and the induced damage. In the literature we can find values that differ of two orders of magnitude: In Campanella and Mitchell (1968), different values are found from $0.01 \mathrm{MPa} /{ }^{\circ} \mathrm{C}$ for clay to $0.05 \mathrm{MPa} /{ }^{\circ} \mathrm{C}$ for sandstone. Palciauskas and Domenico (1982) estimate a value of $0.59 \mathrm{MPa} /{ }^{\circ} \mathrm{C}$ for Kayenta sandstone. On the basis of Sultan (1997) experimental data on Boom clay, Vardoulakis (2002) estimates this coefficient as $0.06 \mathrm{MPa} /{ }^{\circ} \mathrm{C}$. For a clayey fault gouge extracted at a depth of $760 \mathrm{~m}$ in Aigion fault in the Gulf of Corinth (Greece), the value obtained by Sulem et al. (2004) is $0.1 \mathrm{MPa} /{ }^{\circ} \mathrm{C}$ and for intact rock at great depth, the value given by Lachenbruch (1980) is $1.5 \mathrm{MPa} /{ }^{\circ} \mathrm{C}$. For a mature fault at mid-seismogenic depth $(7 \mathrm{~km})$ at normal stress of $196 \mathrm{MPa}$, ambient pore pressure of $70 \mathrm{MPa}$, and ambient temperature of $210^{\circ} \mathrm{C}$, Rice (2006) estimates this coefficient as $0.92 \mathrm{MPa} /{ }^{\circ} \mathrm{C}$ in case of intact fault walls and $0.31 \mathrm{MPa} /{ }^{\circ} \mathrm{C}$ in case of damage fault wall. On the basis of an experimental study on a sandstone, Ghabezloo and Sulem (2009) have emphasized the importance of pressure-dependent compressibility of rocks and pressure and temperature dependent compressibility of pore water on thermal pressurization and have found values between 0.02 and $0.7 \mathrm{MPa} /{ }^{\circ} \mathrm{C}$.

If for simplicity one assumes that the pressurization coefficient $\Lambda$ does not change with temperature and pore pressure, an analytical solution can be obtained for the evolution of the temperature and of the pore pressure in an infinite long shear band under uniform shear for no heat and fluid transfer (Sulem et al., 2005, Rice, 2006). This undrained adiabatic limit is applicable as soon as the slip event is sufficiently rapid considering the low permeability and thermal diffusivity of fault materials. This solution shows that the pore-pressure increases with the slip displacement from its initial hydrostatic value $P_{f}^{0}$ towards its geostatic limit $\sigma_{n}$ (normal stress acting on the shear band), which corresponds to full fluidization. The corresponding temperature rise is simply obtained by dividing the pore pressure rise $\sigma_{n}-P_{f}^{0}$ by the undrained pressurization coefficient $\Lambda$. For example, if one considers a fault at $7 \mathrm{~km}$ depth with an initial hydrostatic pore pressure at $70 \mathrm{MPa}$, a geostatic stress at $180 \mathrm{MPa}$, an initial temperature at $210^{\circ} \mathrm{C}$ and an undrained pressurization coefficient comprised between 0.1 and $1 \mathrm{MPa} /{ }^{\circ} \mathrm{C}$, the temperature rise obtained is between 110 and $1100^{\circ} \mathrm{C}$. This temperature rise must be seen as a lower bound because, as discussed by Rice (2006), the adiabatic and undrained solution appears to be unstable for localization so that the deformation actually localizes in very narrow zones with thickness between few millimeters and few tens of millimeters as observed in mature fault zones. Another idealized situation is met if one assumes that the strain localization zone is infinitely small. This situation corresponds to the model of slip on a plane for which an analytical so- lution has been proposed by Rice (2006). The solution of slip on a plane gives an upper bound for the temperature field and the maximum temperature rise is obtained as $\left(1+\sqrt{\alpha_{h y} / \alpha_{t h}}\right)\left(\left(\sigma_{n}-P_{f}^{0}\right) / \Lambda\right)$ where $\alpha_{h y}$ is the hydraulic diffusivity and $\alpha_{t h}$ is the thermal diffusivity of the medium. For the above example, with $\alpha_{h y}=1$ to $10 \mathrm{~mm}^{2} / \mathrm{s}$ and $\alpha_{t h}=1 \mathrm{~mm}^{2} / \mathrm{s}$, and taking for the undrained pressurization coefficient $\Lambda$ an average value of $0.5 \mathrm{MPa} /{ }^{\circ} \mathrm{C}$, the temperature rise obtained is between 692 and $1440^{\circ} \mathrm{C}$. These simple analytical solutions show that the temperature rise which occurs during a rapid slip event may easily reach the temperature limit for the onset of mineral decomposition. This will be discussed in the next section.

\subsubsection{Thermal decomposition of minerals}

Frictional heat released in a fault zone during seismic slip may induce chemical reactions. Thermal decomposition of minerals for large increase of temperature is potentially a major source of fluid release in the system which may enhance the generation of additional pore pressure excess.

Field evidences that such reactions may take place during an earthquake have been reported in several recent studies. The Taiwan Chelungpu-fault Drilling Project (TCDP) undertaken in 2002 to investigate the faulting mechanism of the 1999 Taiwan Chi-Chi earthquake allowed to recover core samples inside the active fault-zones within the Chelungpu fault. The analysis of these cores showed that the fault core was depleted in carbon relative to the damage zone, and the depletion was attributed to a decomposition of carbonates induced by frictional heat (Hirono et al., 2006a; Hirono et al., 2007, Famin et al. 2008). Hirono et al (2006b) have also measured a higher magnetic susceptibility and a lower density inside the fault core than outside. This high magnetic susceptibility which is degree to which a material can be magnetised by an external magnetic field can be attributed to the decomposition of siderite $\left(\mathrm{FeCO}_{3}\right)$ into magnetite $\left(\mathrm{Fe}_{3} \mathrm{O}_{4}\right)$ with degassing of $\mathrm{CO}_{2}$. Dehydration of hydrous clay minerals during during seismic slip have also been reported by Hirono et al (2008). These authors have observed that the fault core is relatively low in kaolinite and smectite contents as compared to the surrounding zones. This is attributed to the dehydration of interlayer (adsorbed) water (above $200^{\circ} \mathrm{C}$ ) and the dehydroxylation (dehydration of structural water) of kaolinite (above $550^{\circ} \mathrm{C}$ ) and smectite (illitization of smectite above $400^{\circ} \mathrm{C}$ ).

Such reactions of decarbonation of calcite and dehydration of clay minerals have been reproduced experimentally during high velocity friction experiments (Han et al. 2007, Brantut et al. 2008). 


\subsection{4 $\mathrm{CO}_{2}$ degassing during seismic slip}

There is evidence of $\mathrm{CO}_{2}$ release in several active crustal faults. In addition to the relatively low content in inorganic carbon (mainly calcite) in fault core as mentioned above, other field evidences have been reported. In the Corinth rift (Greece) for example, chemical analyzes of water springs near the seismogenic Heliki and Aegion faults revealed an anomalously high content of dissolved $\mathrm{CO}_{2}$ compared with the regional values (Pizzino et al. 2004). The surface trace of the San Andreas fault also displays a positive anomaly of $\mathrm{CO}_{2}$ fluxes (Lewicki and Brantley, 2000), and this $\mathrm{CO}_{2}$ comes from a shallow source, not from the mantle (Lewicki et al., 2003). Moreover, there is growing evidence that $\mathrm{CO}_{2}$ release coincides with seismic slip in crustal faults, active and/or exhumed. Sato and Takahashi (1997) also reported that the $\mathrm{HCO}_{3}{ }^{-}$concentration increased by $30 \mathrm{wt} \%$ in springs located near the Nojima fault (Japan) immediately after the 1995 Kobe earthquake. This carbon discharge, together with other coseismic geochemical anomalies, decreased gradually to normal values in the following ten months. A microinfrared analysis of exhumed pseudotachylites (i.e. friction induced melts produced by seismic slip) from the Nojima fault revealed a carbon supersaturation in the melts, and the quantity of $\mathrm{CO}_{2}$ released by friction melting during the 1995 Kobe earthquake was evaluated to 1.8 to $3.410^{3}$ tons (Famin et al. 2008). These authors emphasize that the carbon had a biogenic isotopic signature both in springs and in the fault rocks, and did not correspond to carbon dioxide degassing from the mantle (Ueda et al., 1999; Arai et al., 2001; Arai et al., 2003; Lin et al., 2003). The $\mathrm{CO}_{2}$ of the Nojima fault might thus be attributed to the decomposition of biogenic carbonates. In the Central Apennines, Italiano et al., (2008) also reported enhanced fluxes of crustal $\mathrm{CO}_{2}$ (i.e. not mantellic) during the 1997-1998 seismic crisis of major faults, and proposed that coseismic decarbonation was responsible for the $\mathrm{CO}_{2}$ emission.

This production of fluid which enhances the increase of pore fluid pressure is in competition with the change of porosity related to the reduction of solid volume induced by the mineral decomposition. Obviously the competing effects of temperature rise (due to shear heating), thermal fluid pressurization, mineral decomposition and porosity/permeability increase induce strong non-linearities in the problem of pore pressure and temperature evolution of a rapidly sheared fault zone. The kinetics of the chemical reaction of mineral decomposition is also a major factor that competes with heat and fluid diffusion processes. The endothermic character of the chemical reaction plays also a major role in the energy balance of the system as a large part of the frictional heat is consumed into the mineral decomposition (Hamada et al. 2009). As shown by Sulem and Famin (2009) and Brantut et al (2010), these chemi- cal reactions which are thermally activated limit the temperature increase which tends to stabilize to a value slightly higher than the temperature of onset of the reaction.

\section{THERMO-HYDRO-MECHANICAL MODEL- ING OF RAPID SLIP IN CARBONATE ROCKS}

\subsection{Kinetics of thermal decomposition of calcite}

We focus here on the kinetics of chemical decomposition of calcite (decarbonation) because carbonates are present in every fault zones from the ductilebrittle transition $(\sim 15 \mathrm{~km})$ to the subsurface, and because, as mentioned above, there is evidence of $\mathrm{CO}_{2}$ release in several active crustal faults.

The rate of emitted $\mathrm{CO}_{2}$ is evaluated using the kinetics of the chemical reaction of calcite thermal decomposition:

$$
\mathrm{CaCO}_{3} \rightarrow \mathrm{CaO}+\mathrm{CO}_{2}
$$

The reacted fraction, $\alpha(0 \leq \alpha \leq 1 ; \alpha=1$ if the entire substance is reacted) is expressed by the Arrhenius equation (L'vov 2002):

$$
\frac{\partial \alpha}{\partial t}=f(\alpha) A \exp \left(-\frac{E_{a}}{R T}\right)
$$

where $f(\alpha)$ is a kinetic function determined by the reaction mechanism, $A$ is a constant (pre-exponential term of the Arrhenius law), $E_{a}$ is the activation energy of the reaction, $R$ is the gas constant (8.31447JK-1mol-1). In the following we will take the values corresponding to $\mathrm{CaCO} 3$ mixed with silica: $\quad E_{a}=319000 \mathrm{Jmol}^{-1}, A=2.95 \times 10^{15} \mathrm{~s}^{-1} \quad$ (Dollimore et al., 1996). For thermal decomposition of calcite the kinetic function given by Criado et al. $(1995)$ is $f(\alpha)=(1-\alpha)^{2 / 3}$.

\subsection{Position of the problem}

Considering that the length scales in the direction parallel to the fault over which the thermo-poromechanical fields vary are much larger than in the direction normal to it, we analyse here a 1D problem. We consider a rapidly deforming and infinitely long shear band of thickness $h$ consisting of fluidsaturated material. This shear band begins to undergo slip $\delta$ at a time $t=0$ with an imposed overall slip-rate $V$ in the $\mathrm{x}$-direction, as shown in figure 1. Inside such a shear-band the pore pressure $P_{p}$, the temperature $T$, and the velocity $v$ are assumed to be functions only of time $t$ and of the position $z$ in the direction normal to the band (Fig. 2).

For the pore pressure and temperature range considered here for which the decarbonatation of $\mathrm{CO}_{2}$ is active ( $T \geq 700^{\circ} \mathrm{C}$ and $\left.P_{p} \geq 70 \mathrm{MPa}\right)$, water and carbon dioxide are in supercritical state. They are miscible and their compressibility, viscosity, density and 
thermal expansion coefficient are nearly equal. Thus, for simplicity, it is assumed that the porous space is saturated with a unique fluid, with the thermodynamic properties of water.

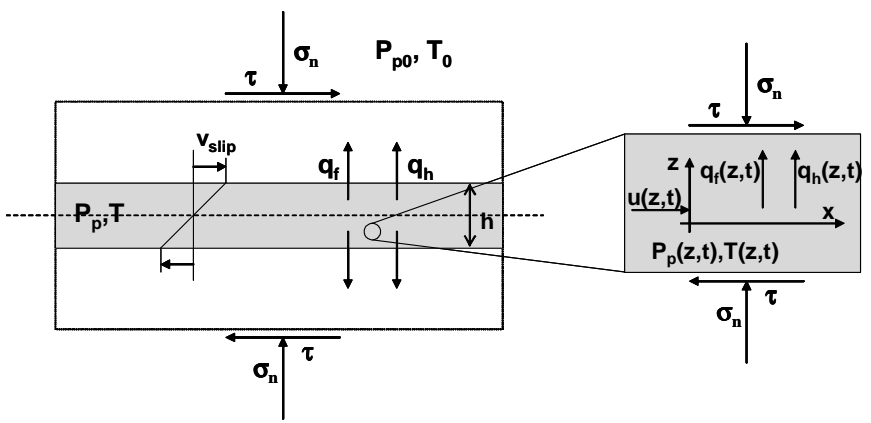

Figure 2. Model of a deforming shear-band with heat and fluid fluxes

\subsection{Governing equations}

The governing equations are derived from the conservation and transport equations (Vardoulakis and Sulem, 1995). The reader can refer to Sulem and Famin (2009) and Sulem et al. (2009) for the details of the derivations.

\subsubsection{Fluid mass conservation}

The production/diffusion equation for the pore pressure is obtained from the mass balance equations and is expressed as the sum of four terms: the diffusion term, the thermal pressurization term, the term corresponding to the fluid released in the system by the chemical reaction and the term corresponding to the effect on pore pressure of inelastic porosity change:

$\frac{\partial P_{p}}{\partial t}=-\frac{1}{\rho_{f} \beta} \frac{\partial q_{f}}{\partial z}+\Lambda \frac{\partial T}{\partial t}+\frac{1}{\rho_{f} \beta} \frac{\partial m_{d}}{\partial t}-\frac{1}{\beta} \frac{\partial n_{d}}{\partial t}$

In the above equation,

- $\rho_{f}$ is the density of the saturating fluid;

- $\beta$ is the (elastic) volumetric pore fluid storage coefficient: $\beta=n\left(\beta_{f}+\beta_{n}\right)$ where $n$ is the pore volume fraction (Lagrangian porosity), $\beta_{f}=\frac{1}{\rho_{f}}\left(\frac{\partial \rho_{f}}{\partial P_{p}}\right)_{T}$ is the pore fluid compressibility and $\beta_{n}=\frac{1}{n}\left(\frac{\partial n}{\partial P_{p}}\right)_{T}$ is the pore volume compressibility;

- $q_{f}$ is the fluid mass flux and is evaluated assuming Darcy's law for fluid flow with viscosity $\eta_{f}$ through a material with permeability $k_{f}: q_{f}=-\frac{\rho_{f}}{\eta_{f}} k_{f} \frac{\partial P_{p}}{\partial z}$;
- $\Lambda=\frac{\lambda_{f}-\lambda_{n}}{\beta_{n}+\beta_{f}}$ is the undrained thermo-elastic pressurization coefficient (Rice, 2006), where $\lambda_{f}=-\frac{1}{\rho_{f}}\left(\frac{\partial \rho_{f}}{\partial T}\right)_{P_{p}}$ is the pore fluid thermal expansion coefficient and $\lambda_{n}=\frac{1}{n}\left(\frac{\partial n}{\partial T}\right)_{P_{p}}$ is the thermal expansion coefficient of the pore volume, which is equal to the thermal expansion coefficient of the solid fraction for thermo-poro-elastic materials;

- $m_{d}$ is the mass per unit volume of the fluid released in the system by mineral decomposition; Using the kinetic function for the considered chemical reaction (equation (2)) the rate of the released fluid is simply given by:

$$
\frac{\partial m_{d}}{\partial t}=\left(m_{0}-m_{d}\right) \frac{\partial \alpha}{\partial t}
$$

where $m_{0}=\chi \rho_{\mathrm{CaCO}_{3}}\left(1-n_{0}\right)$ is the total mass of calcite that can be decomposed ( $n_{0}$ is the initial porosity, and $\chi$ is the ratio between the molar mass $M_{\mathrm{CO} 2}$ of $\mathrm{CO}_{2}(44 \mathrm{~g} / \mathrm{mol})$ and the molar mass $M_{\mathrm{CaCO} 3}$ of calcite $(100 \mathrm{~g} / \mathrm{mol}))$.

- $\frac{\partial n_{d}}{\partial t}$ is the rate of inelastic porosity change; this term includes the effect of co-seismic dilatancy, induced by fault surface irregularities and the effect of the decomposition of the solid phase. If we neglect the co-seismic dilatancy and assume that inelastic porosity change is only due to the change of solid mass, we can relate it to the mass of released fluid:

$$
\begin{aligned}
& \frac{\partial n_{d}}{\partial t}=-\frac{1}{\rho_{\mathrm{CaCO}_{3}}} \frac{\partial m_{\mathrm{CaCO}_{3}}}{\partial t}-\frac{1}{\rho_{\mathrm{CaCO}}} \frac{\partial m_{\mathrm{CaO}}}{\partial t}=\xi \frac{\partial m_{d}}{\partial t} \\
& \text { with } \xi=\frac{1}{\rho_{\mathrm{CaCO}_{3}}} \frac{M_{\mathrm{CaCO}_{3}}}{M_{\mathrm{CO}_{2}}}-\frac{1}{\rho_{\mathrm{CaCO}}} \frac{M_{\mathrm{CaO}}}{M_{\mathrm{CO}_{2}}}
\end{aligned}
$$

where $\rho_{\mathrm{CaCO} 3}$ (resp. $\rho_{\mathrm{CaO}}$ ) and $M_{\mathrm{CaCO} 3}$ (resp. $M_{\mathrm{CaO}}$ ) are the density and the molar mass of $\mathrm{CaCO}_{3}$ (resp. $\mathrm{CaO})$.

\subsubsection{Energy conservation}

Let $E_{F}$ be the rate of frictional heat produced during slip and $E_{C}$ the rate of heat used in the endothermic thermal decomposition. The equation of conservation of energy is expressed as

$\rho C \frac{\partial T}{\partial t}=E_{F}-E_{C}-\frac{\partial q_{h}}{\partial z}$

where $\rho C$ is the specific heat per unit volume of the fault material in its reference state and $q_{h}$ is the heat flux. It is assumed that all the plastic work is con- 
verted into heat and thus $E_{F}=\tau \frac{\partial v}{\partial z}$. On the other hand, the rate of heat used in the chemical reaction can be expressed from the enthalpy change of the reaction and the rate of reacted fraction as $E_{C}=\Delta_{r} H_{T}^{0} \frac{\partial m_{d}}{\partial t}$. The heat flux is related to the temperature gradient by Fourier's law, $q_{h}=-k_{T} \frac{\partial T}{\partial z}$ where $k_{T}$ is the thermal conductivity of the saturated material. In equation (6) it is assumed that all heat flux is due to heat conduction neglecting heat convection by the moving hot fluid. This assumption is justified by the low pore volume fraction and the low permeability of fault gouges (Lee and Delaney, 1987). However, this assumption should be relaxed in case of a seismically-induced high permeability in the wall rocks of the fault.

\subsubsection{Momentum balance}

The 1D-momentum balance equation reads as

$\frac{\partial \tau}{\partial z}=\rho \frac{\partial v}{\partial t}$

As discussed by Rice (2006), the effect of even large accelerations like several times the acceleration of the gravity $\mathrm{g}$ is insignificant over the small length scales in the $\mathrm{z}$-direction normal to the fault where the heat and fluid diffusion process are taking place during rapid slip and very high values of pressure and temperature gradients. For example, assuming an acceleration of $10 \mathrm{~g}$ and a specific mass of the material of $2500 \mathrm{~kg} / \mathrm{m}^{3}$ would result in a change of $2.5 \times 10^{-2} \mathrm{MPa} / \mathrm{m}$ for $\tau$. The relevant length scale in $\mathrm{z}-$ direction is only few $\mathrm{cm}$ and thus the variation for $\tau$ can be neglected and mechanical equilibrium can be assumed:

$\frac{\partial \tau}{\partial z}=0$

Consequently, as the shear stress is constant in space, the Coulomb friction law cannot be assumed to be met in all deforming regions unless the pore pressure is also constant in space as it is the case in the undrained adiabatic limit. It is thus assumed that the frictional resistance is proportional to the mean effective stress inside the band:

$\tau(t)=f\left(\sigma_{n}-\frac{1}{h} \int_{-h / 2}^{h / 2} P_{p}(\xi, t) d \xi\right)$

where $f$ is the friction coefficient of the gouge and $h$ is the width of the shear-band. From the equation of momentum balance we obtain a linear distribution for the velocity field corresponding to homogeneous straining:

$$
v=V \frac{z}{h / 2}
$$

\section{NUMERICAL EXAMPLES}

\subsection{Thermal pressurization in faults at shallow depth}

The first example presented here refers to Aigion fault (Cornet et al, 2004a,b). The experimental characterization program performed on fault zone cores extracted from Aigion fault at a depth of $760 \mathrm{~m}$ has shown that the Aigion fault gouge is a clay-rock mixture (Sulem et al., 2004). The mineral composition of the clayey gouge exhibits a large content of quartz $(74 \%)$, some hydrous minerals (chlorite, 2$3 \%$ and illite $8-12 \%$ ) and also a small content of albite $(8-13 \%)$ and hematite $(2-3 \%)$. Although the clay fraction is relatively small, it has a significant influence on the thermo-mechanical properties of the material. The clayey core of the fault has a very low fluid permeability of about $10^{-19} \mathrm{~m}^{2}$ and exhibits contractant volumetric behavior when heated. This behavior is typical of normally consolidated clays (Hueckel and Pellegrini, 1991, Sultan et al. 2002.) The sensitive parameter for the description of the thermo-poro-mechanical coupling is the thermal pressurization coefficient of the material. It was found that at a nominal effective stress corresponding to $760 \mathrm{~m}$ deep conditions, this coefficient is about $0.1 \mathrm{MPa} /{ }^{\circ} \mathrm{C}$ (Sulem et al. 2007).

Assuming that the density of the overburden is $2500 \mathrm{~kg} / \mathrm{m}^{3}$, we estimate a total vertical stress of about $19 \mathrm{MPa}$ for a depth of $760 \mathrm{~m}$. The hydrostatic initial pore pressure is $7.6 \mathrm{MPa}$ and the temperature recorded from thermal logs at $760 \mathrm{~m}$ is $28^{\circ} \mathrm{C}$.

In order to demonstrate the importance of the shear band thickness, two computations assuming a thickness of $1 \mathrm{~mm}$ and $0.5 \mathrm{~mm}$ respectively have been performed. A constant slip velocity of $1 \mathrm{~m} / \mathrm{s}$ is imposed. The friction coefficient of the gouge material is taken equal to $f=0.5$ (Sulem et al. 2004). In the first one, the liquefaction limit $\left(P_{p}=\sigma_{n}\right.$, i.e. full fluidization of the gouge), is reached after $0.13 \mathrm{~s}$ of shearing (Fig. 3a). The corresponding temperature reached in the centre of the sheared is $142^{\circ} \mathrm{C}$. In the second case for which the shear band thickness which is twice smaller $(\mathrm{h}=0.5 \mathrm{~mm})$, the computed results show that the temperature increase is much higher and that vaporization of the pore fluid occurs (Fig. 3b) before liquefaction. This state is reached at $\mathrm{t}=1.4 \mathrm{~s}$ for which in the centre of the band $P_{p}=17 \mathrm{MPa}$ and $\mathrm{T}=356^{\circ} \mathrm{C}$. Note that fluid vaporization is possi- 
ble only if it is assumed that the soil is not fully saturated.

We observe that at shallow depth, the pore fluid pressurization limits the temperature increase so that no mineral decomposition occurs.

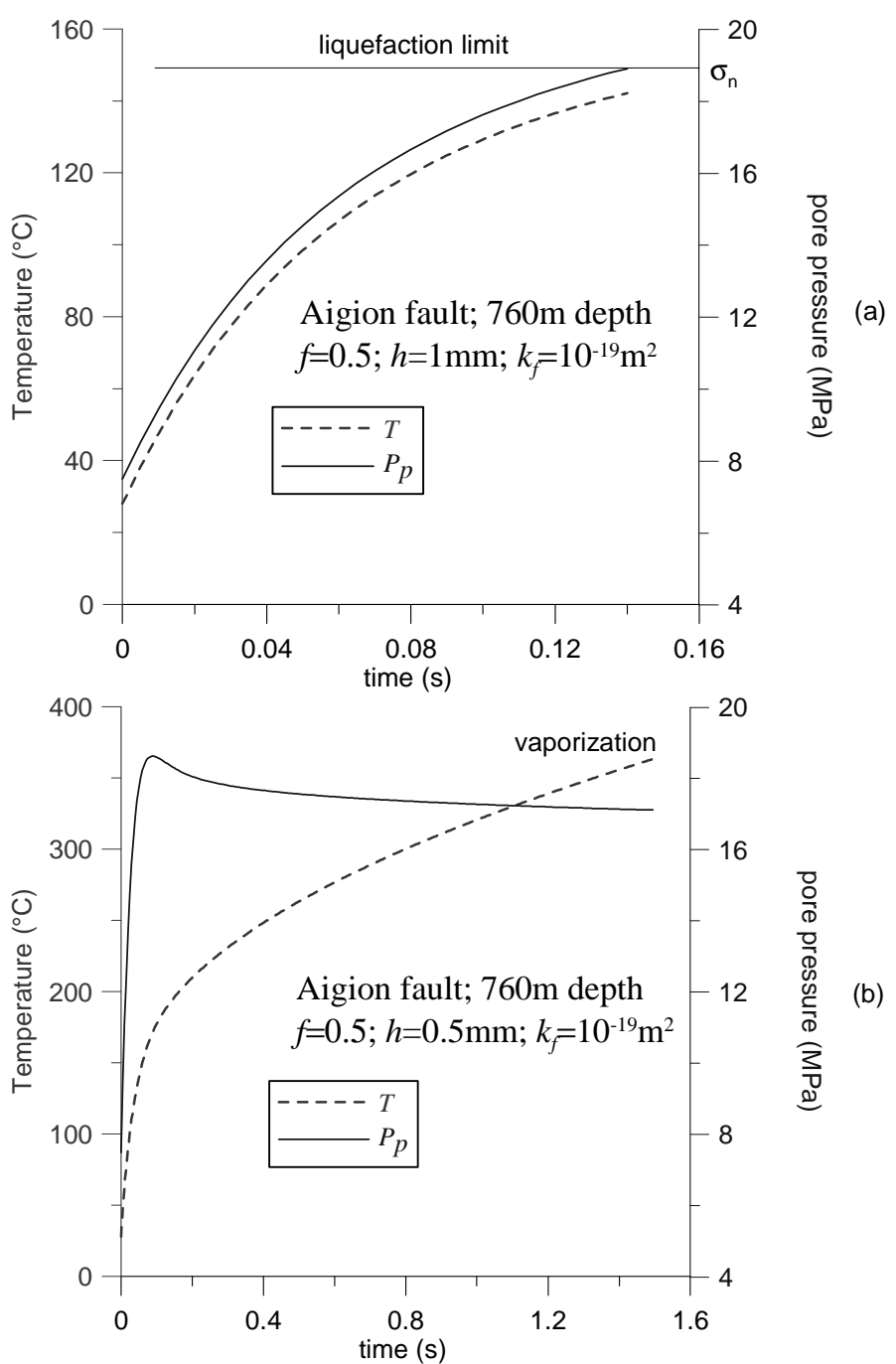

Figure 3. Aigion fault; Temperature and pore pressure vs time at the center of the band; slip velocity $=1 \mathrm{~m} / \mathrm{s}$ (a) Shear band thickness $=1 \mathrm{~mm}$, liquefaction occurs at $\mathrm{t}=0.13 \mathrm{~s}$; (b) Shear band thickness $=0.5 \mathrm{~mm}$, vaporization of the pore fluid is reached at $1.4 \mathrm{~s}$.

\subsection{Fault in carbonate rocks at mid-seismogenic depth}

We consider here a fault at $7 \mathrm{~km}$ depth in a carbonate rock with an initial hydrostatic pore pressure at $70 \mathrm{MPa}$, a geostatic stress at $180 \mathrm{MPa}$, an initial temperature at $210^{\circ} \mathrm{C}$. The thermal expansion coefficient is $\lambda_{n}=2.4 \times 10^{-5}\left({ }^{\circ} \mathrm{C}\right)^{-1}$. For the pore volume compressibility, we account for the effect of effective stress change due to pore pressure rise. The expression of the pore volume compressibility is obtained from poro-elasticity theory and is given by Rice (2006) as:

$$
\beta_{n}=\frac{1}{n}\left(\beta_{d}-(1+n) \beta_{s}\right)
$$

where $\beta_{s}$ is the compressibility of the solid phase $\left(1.25 \times 10^{-5} \mathrm{MPa}^{-1}\right.$ for calcite) and $\beta_{d}$ is the drained compressibility of the porous rock. We consider here the empirical expression for the effective stress dependent drained compressibility as proposed by Wibberley and Shimamoto (2005) for the Median Tectonic line fault zone in Japan:

$$
\begin{aligned}
& \beta_{d}=2.5 \times 10^{-4} \exp \left(-1.38 \times 10^{-2}\left(\sigma_{n}-P_{p}\right)\right), \\
& \text { with } \beta_{d} \text { in } \mathrm{MPa}^{-1} \text { and }\left(\sigma_{n}-P_{p}\right) \text { in } \mathrm{MPa}
\end{aligned}
$$

(a) The initial porosity of the rock is taken equal to 0.03 . The density of the porous rock is taken equal to $\rho=2.6 \mathrm{~g} / \mathrm{cm}^{3}$, the density of the solid phase (calcite) is $\rho_{s}=2.71 \mathrm{~g} / \mathrm{cm}^{3}$, and the specific heat is $\rho C=2.7 \mathrm{MPa} /\left({ }^{\circ} \mathrm{C}\right)$. We assume a slip velocity of $1 \mathrm{~m} / \mathrm{s}$. In the computations we account for the changes of the physical properties of the saturating fluid (here water) (Wagner and Pruss, 2002).

The decomposition of carbonate can induce substantial change in the porosity of the rock which affects the permeability. It is known that there is no unique relationship between porosity and permeability applicable to all porous media and that the geological evolution process of the pore space influence the permeability-porosity relationship. The empirical power law $k_{f} \propto n^{\alpha}$ is commonly used for geomaterials. The exponent $\alpha$ characterizes the porosity sensitivity of permeability and can take values ranging from 1 to 25 (David et al., 1994). The high values of $\alpha$ correspond in general to rocks with a high porosity whereas for low porosity rocks law values of $\alpha$ are obtained. The commonly used cubic Carman Kozeny permeability law is assumed here to take into account the effect of porosity change due to mineral decomposition on the permeability of the rock:

$k_{f}=k_{f 0}\left(\frac{1-n_{0}}{1-n}\right)^{2}\left(\frac{n}{n_{0}}\right)^{3}$

where $k_{f 0}$ is the reference permeability corresponding to the reference porosity $n_{0}$. The assumed permeability law has a strong effect on the numerical results and there is a need for experimental data on permeability changes resulting from the particular process of carbonate decomposition. According to Milsch et al. (2003), the fluid transport occurs as a local process on the grain scale and therefore it is expected that inside the slip zone, where intense grain comminution and production of very fine particles occur, the reaction induces strong changes of permeability.

The recent high velocity shear experiments on Carrara marble of Han et al. (2007) have shown that the friction coefficient decreases rapidly to values as 
low as 0.06 due to the thermal decomposition of calcite induced by frictional heating. Here, we take $f=0.1$.

We assume that the initial permeability of the intact medium is $k_{f 0}=10^{-18} \mathrm{~m}^{2}$. The shear band thickness is taken equal to $5 \mathrm{~mm}$.

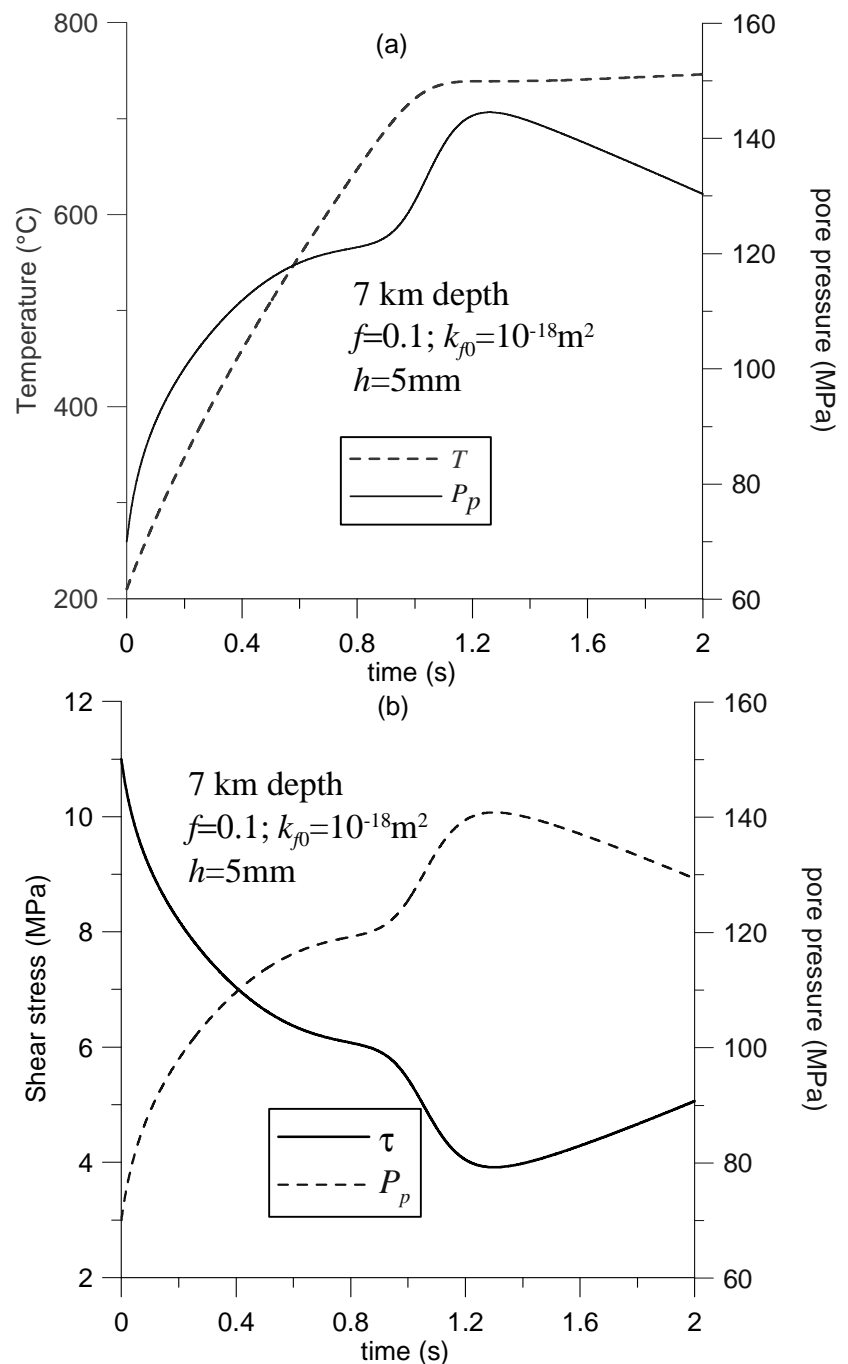

Figure 4. Fault at $7 \mathrm{~km}$ depth: (a) Evolution of temperature and pore pressure in the centre of the shear band, (b) evolution of the shear stress.

The computed results are presented in figure 4 . The evolution in time of the temperature and the pore pressure in the centre of the band is plotted in figure $4 \mathrm{a}$. Considering the constant slip velocity of 1 $\mathrm{m} / \mathrm{s}$, this graph can also be seen as the evolution of temperature and pore pressure with accumulated slip. The corresponding shear stress is plotted in figure $4 \mathrm{~b}$. These results show the coupling effect of heat which induces first a pore pressure increase. When the decomposition of the carbonate rock begins at about $700{ }^{\circ} \mathrm{C}$, the temperature increase is drastically slowed due to the energy consumed in the endothermic chemical reaction.

Two competing effects act on the evolution of the pore pressure: on one hand the production of $\mathrm{CO}_{2}$ induces an additional fluid mass and thus a pressurization of the pore fluid; on the other hand the in- crease of porosity due to the solid decomposition induces an increase of the permeability of the medium which limits the pressurization. The pore pressure in the centre of the band exhibits a maximum of about $145 \mathrm{MPa}$ which does not exceed the total normal stress acting (180MPa) on the band which means that full liquefaction is not reached. As mentioned above, through the friction law the shear stress is related to the mean effective stress inside the band (figure 4b). Consequently, the shear stress decreases rapidly during initial pressurization and then increases again. Thus, the mineral decomposition of the rock can be seen as a mechanism of fault weakening in a first stage then fault re-strengthening in a second stage.
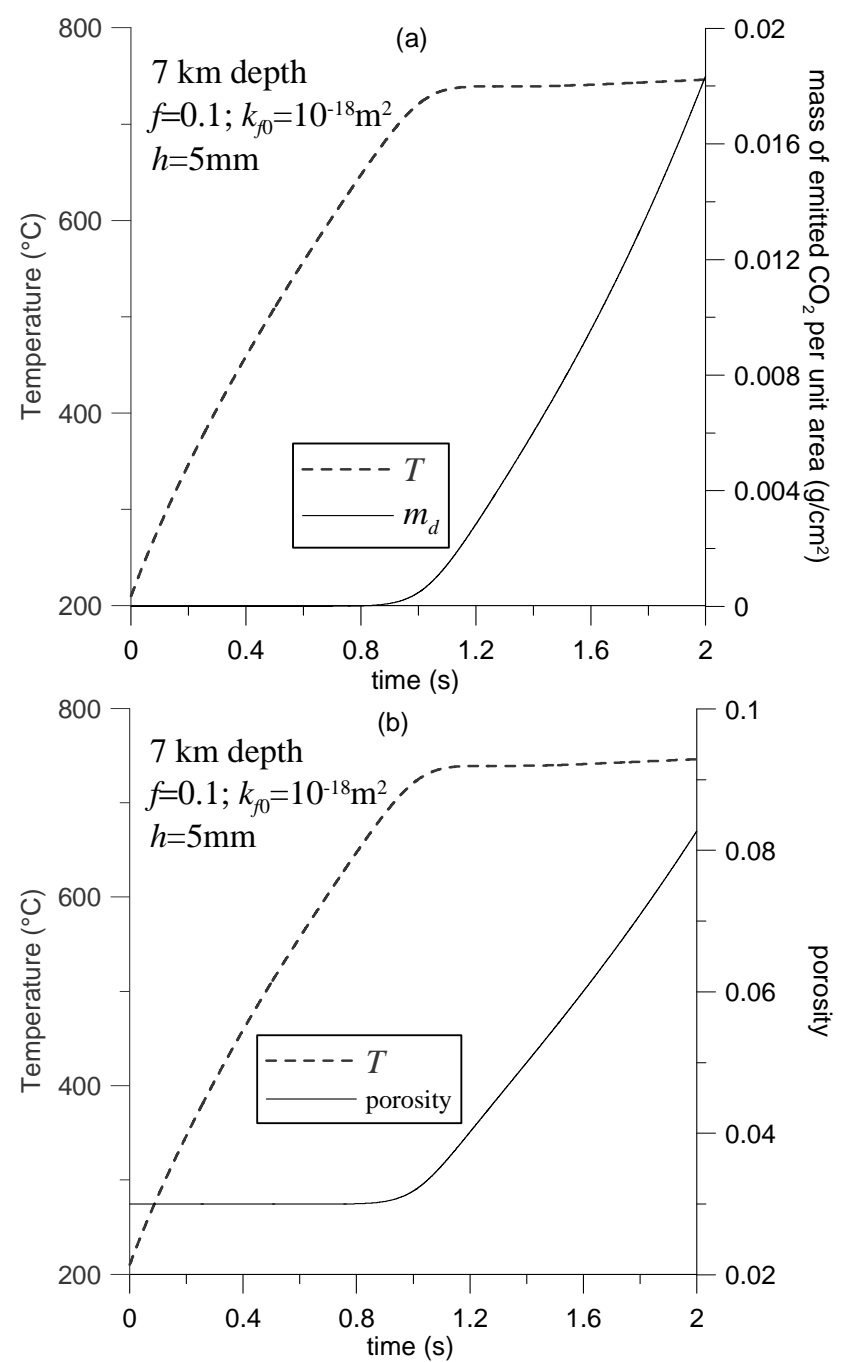

Figure 5. Fault at $7 \mathrm{~km}$ depth: (a) Evolution of the mass of emitted $\mathrm{CO} 2$, (b) evolution of the porosity in the centre of the band.

The accumulated mass per unit area of the fault plane of emitted $\mathrm{CO}_{2}$ is plotted in figure 5a. After one second, the temperature reaches a quasi constant state and the production rate is almost constant. These results show that the mass of emitted $\mathrm{CO}_{2}$ after $2 \mathrm{~s}$ is about $0.018 \mathrm{~g} / \mathrm{cm} 2$. The corresponding rate of emitted $\mathrm{CO}_{2}$ is about $180 \mathrm{t} / \mathrm{s}$ per $\mathrm{km}^{2}$ of fault zone. The corresponding solid mass change is shown through the evolution of the porosity in the centre of the shear band (Fig. 5b). 


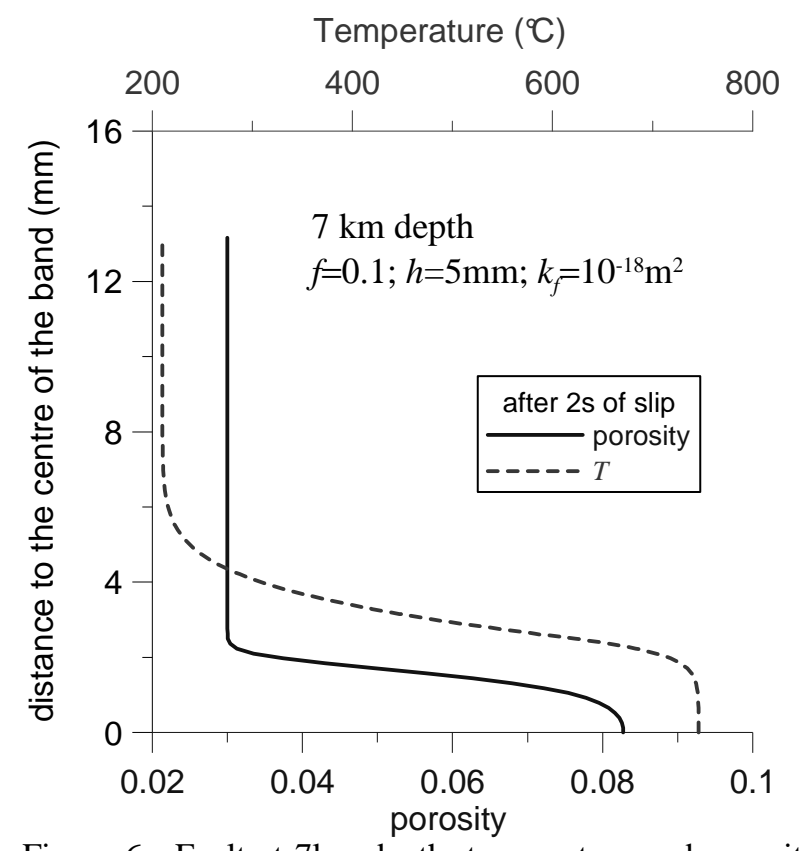

Figure 6. Fault at $7 \mathrm{~km}$ depth: temperature and porosity fields after 2 s slip.

The temperature field around the centre of the band is shown in figure 6 for $t=2 \mathrm{~s}$, with the corresponding value of the porosity. These plots show that the temperature increase is localized in the central zone of the band. The porosity is affected only in zones where the temperature exceeds $700^{\circ} \mathrm{C}$ which for the considered computation corresponds to a width of about $4 \mathrm{~mm}$.

The effect of mineral decomposition is also shown in figure 7 where the results of the above computation are compared to the ones obtained without $\mathrm{CO}_{2}$ emission. In this latter case only thermal pressurization occurs. If no mineral decomposition occurs, the pore pressure increase is slower and for the considered parameters, the maximum pore pressure is about $120 \mathrm{MPa}$ and consequently the temperature increase is much stronger and melting of the rock can possibly occur (the melting temperature is about $1600^{\circ} \mathrm{C}$ for calcite).

\section{CONCLUSION}

In the last thirty years, the study of earthquake mechanisms has emphasized the major role of rock friction. Earthquakes appear to be the result of a frictional instability and occur by sudden slippage along a pre-existing fault. Therefore, the understanding of the nature of the friction on faults during the interseismic periods and during earthquakes is essential to assess the hazards of seismic rupture.

The presence of fluids greatly affects the frictional resistance of a fault. Pore fluid pressurization under shear heating is a mechanism of thermal softening. When thermal softening prevails against strain or strain rate hardening, dynamic plastic localization in the form of adiabatic shear banding is known to occur at high strain rates under quasi adia- batic conditions. The phenomenon of adiabatic shear banding is well known in metal plasticity for metal cutting and impact problems (e.g. Wright, 2002). The extreme thinness of the sheared zone revealed by field observations of mature faults suggest that it is the result of a plastic instability in the form of shear localization as shown by Rice (2005) because uniform undrained adiabatic shearing of a layer is actually unstable.
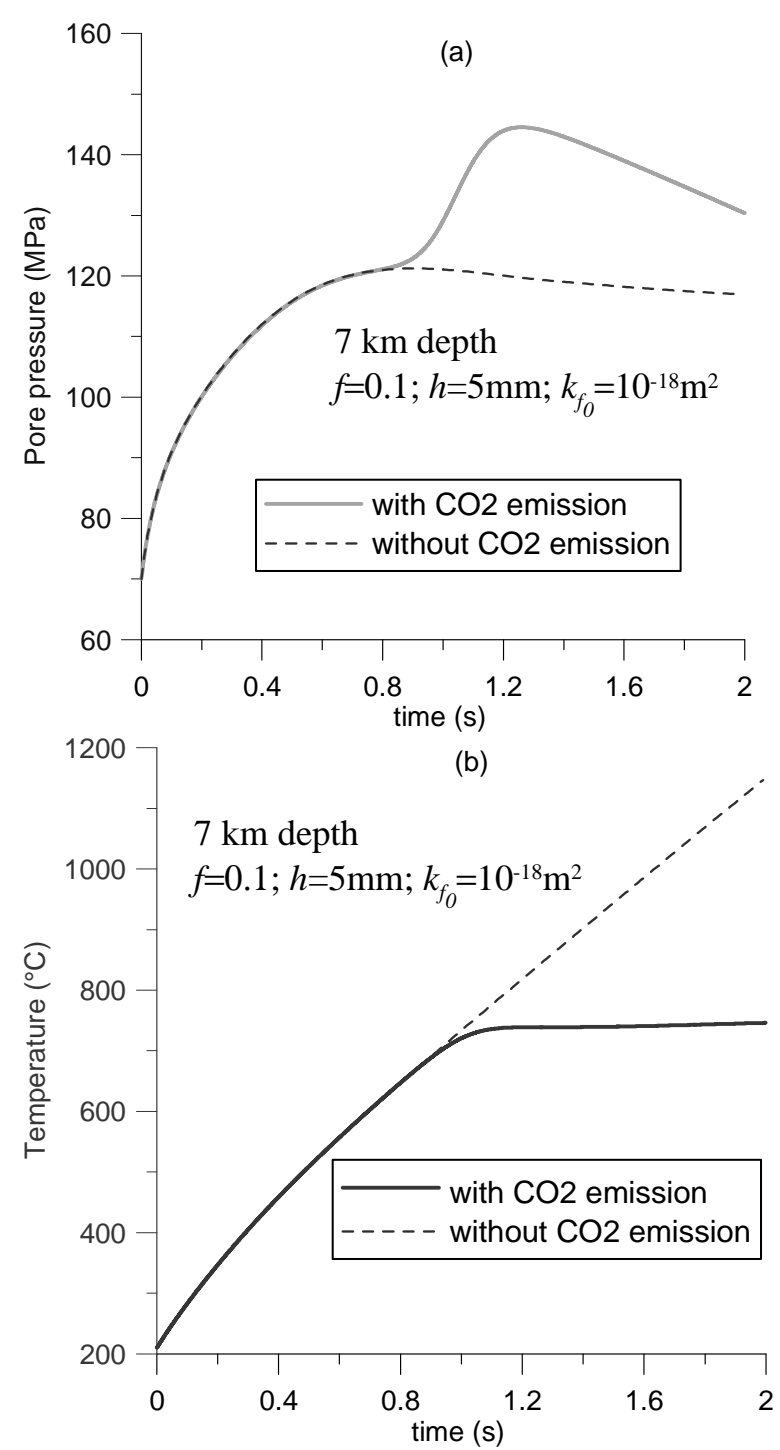

Figure 7. Fault at $7 \mathrm{~km}$ depth: Effect of $\mathrm{CO} 2$ emission on the evolution of temperature (a) and pore pressure (b) in the centre of the shear band.

Frictional weakening mechanisms allow to explain the acceleration of sliding during nucleation of an earthquake and also the lack of pronounced heat outflow, and lack of at least shallow frictional melting, along major tectonic faults.

Shear heating can lead to fluid vaporization at shallow depth and mineral decomposition at midseismogenic depth. Indeed, thermal decomposition of minerals appears to be an important physical process in the phenomenon of thermal heating and pore fluid pressurization during seismic slip. The combined effects of frictional heating, temperature rise, endothermic mineral decomposition, pore pres- 
sure rise, porosity and permeability increase result in highly coupled and competing processes.

In this paper, the effect of carbonate decomposition is emphasized because carbonates are present in every fault zones from the ductile-brittle transition $(\sim 15 \mathrm{~km})$ to the subsurface, and because, as revealed by field observations, there is evidence of $\mathrm{CO}_{2}$ release in several active crustal faults. A first essential result of the analysis is that the endothermic reaction of calcite decomposition limits the co-seismic temperature increase to less than $\sim 800{ }^{\circ} \mathrm{C}$ (corresponding to the initiation of the chemical reaction) within a carbonate shear band under rapid slip. Decarbonation is only one of the possible thermal reactions of mineral decomposition. Phyllosilicates are common secondary minerals in faults and their reaction of thermal dehydration is also endothermic. Therefore, it is likely that the reaction-induced temperature limitation obtained in our model may apply qualitatively to most fault zones. In this case, mature faults with a long history of slip and a large cumulated displacement are likely more prone to reaction-induced temperature limitation than recent faults, because of their larger content in volatile-rich secondary minerals. In the recent study of Brantut et al. (2010), the authors show that the temperature rise in the slipping zone is stopped while the dehydration reaction progresses. This would provide another explanation to the notorious absence of positive heat flow anomaly on active crustal faults such as San Andreas (Lachenbruch and Sass 1980): a large part of the heat produced by friction would be consumed by endothermic reactions. Another consequence is that friction melting is hampered by endothermic calcite decomposition in carbonate fault rocks, and probably in other faults containing a sufficiently high proportion of volatile-rich secondary minerals. This is consistent with the relative scarcity of pseudotachylytes in mature faults.

The second essential implication of the above analysis is that decarbonation is a source of $\mathrm{CO} 2$ that significantly increases the slip-weakening effect of thermal pressurization. The pore fluid pressure exhibits an initial phase of increase due to thermal pressurization, then a sudden acceleration of generated pore pressure when the solid decomposition is activated. However, the increase of permeability limits the pore pressure that reaches a maximum and then decreases. The numerical results reproduce this pore pressure pulse and the initial fault weakening followed by a re-strengthening of the shear stress.

Our model of thermal pressurization, taking into account these coupled processes, provides a robust framework for estimating the dynamic friction of faults and the energy balance of earthquakes.

\section{ACKNOWLEDGEMENTS}

This work is dedicated to the memory of Ioannis Vardoulakis as recognition for a long standing cooperation and a deep friendship. I also wish to thank Nicolas Brantut, Vincent Famin, Jim Rice and Alexandre Schubnel for fruitful discussions.

\section{REFERENCES}

Arai, T., Okusawa, T., and Tsukahara, H., 2001. Behavior of gases in the Nojima Fault Zone revealed from the chemical composition and carbon isotope ratio of gases extracted from DPRI $1800 \mathrm{~m}$ drill core, The Island Arc, 10 (3-4): 430-438,.

Arai, T., Tsukahara, H., and Morikiyo, T., 2003. Sealing process with calcite in the Nojima active fault zone revealed from isotope analysis of calcite, Journal of Geography, 112 (6): 915-925.

Anderson, D. L. 1980. An earthquake induced heat mechanism to explain the loss of strength of large rock and earth slides", In P. Karasudhi et al. (eds), Engineering for Protection from Natural Disasters, J. Wiley, New York.: 569-580.

Beeler, N. M., Tullis, T. E. and Goldsby D. L. 2008. Constitutive relationships and physical basis of fault strength due to flash heating, J. Geophys.Res., 113, B01401.

Boullier A.M., Ohtani T., Fujimoto K. and Ito H. 2001. Fluid inclusions in pseudotachylites from the Nojima fault, Japan, J. Geophys. Res.106(B10):. 21965-21977.

Brantut, N., Schubnel A., Rouzaud J.-N., Brunet F., and Shimamoto T. (2008), High-velocity frictional properties of a clay-bearing fault gouge and implications for earthquake mechanics, J. Geophys. Res., 113, B10401.

Brantut, N., Schubnel A., Corvisier, J., and Sarout, J. 2010, Thermo-chemical pressurization of faults during coseismic slip, J. Geophys. Res., in print.

Cocco, M, Spudich P, \& Tinti, E. 2006. On the mechanical work absorbed on faults during earthquake ruptures. In R. Abercrombie et al. (eds.), Radiated Energy and the Physics of Faulting, Geophys. Monogr. Ser., vol. 170, AGU, Washington, D. C., 237-254.

Cornet, F., Bernard, P., Moretti, I., 2004a. The Corinth Rift Laboratory, Comptes Rendus Geosciences, 336 (4-5): 235242.

Cornet, F., Doan, M.L., Moretti, I., and Borm, G., 2004b. Drilling through the active Aigion Fault: the AIG10 well observatory, Comptes Rendus Geosciences, 336 (4-5): 395-406.

Criado, J. M., Gonzalez, M., Malek, J,. and Ortega, A., 1995. The effect of the $\mathrm{CO} 2$ pressure on the thermal decomposition kinetics of calcium carbonate, Thermochemica Acta, 254: 121-127.

David C, Wong T-F, Zhu W and Zhang, J. 1994. Laboratory measurement of compaction-induced permeability change in porous rocks: Implications for the generation and maintenance of pore pressure excess in the crust, Pure and Applied Geophysics, 143: 425-456.

Di Toro, G., Goldsby D. L., and Tullis T. E. 2004. Friction falls toward zero in quartz rock as slip velocity approaches seismic rates, Nature, 427: 436-439.

Di Toro, G., Nielsen S., and Pennacchioni G. 2005. Earthquake rupture dynamics frozen in exhumed ancient faults, Nature, 436: 1009-1012.

Di Toro, G., Hirose T., Nielsen S., Pennacchioni G., and Shimamoto T. 2006. Natural and experimental evidence of melt lubrication of faults during earthquakes, Science, 311: 647-649. 
Dollimore, D., Tong, P., and Alexander, K. S., 1996. The kinetic interpretation of the decomposition of calcium carbonate by use of relationships other than the Arrhenius equation, Thermochimica Acta, 282/283: 13-27.

Famin, V., Nakashima S. , Boullier A.-M., Fujimoto K., and Hirono T. 2008. Earthquake produce carbon dioxide in crustal faults, Earth and Planetary Science Letters, 265, 34, 30, 487-497.

Ghabezloo, S. \& Sulem, J., 2009. Stress dependent thermal pressurization of a fluid-saturated rock. Rock Mechanics and Rock Engineering, 42: 1-24.

Habib, P. 1967. Sur un mode de glissement des massifs rocheux, Comptes Rendus Hebd. Seanc. Acad. Sci., Paris, 264: 151-153.

Habib, P. 1976. Production of gaseous pore pressure during rock slides, Rock Mech., 7: 193-197.

Hamada, Y., Hirono T., Tanikawa W., Soh W., and Song S., 2009. Energy taken up by co-seismic chemical reactions during a large earthquake: An example from the 1999 Taiwan Chi-Chi earthquake, Geophys. Res. Lett., 36: L06301.

Han, R., Shimamoto T., Hirose T., Ree J.-H. and Ando J. 2007, Ultralow friction of carbonate faults caused by thermal decomposition, Science, 316: 878-881.

Hirono, T., Ikehara M., Otsuki K., Mishima T., Sakaguchi M., Soh W., Omori M., Lin W., Yeh E., Tanikawa W., and Wang C.Y. 2006a. Evidence of frictional melting from diskshaped black material, discovered within the Taiwan Chelungpu fault system, Geophysical Research letters, 33 L19311.

Hirono, T., Lin, W., Yeh, E-S., Soh, W., Hashimoto, Y., Sone, H., Matsubayashi, O., Aoike, K., Ito, H., Kinoshita, M., Murayama, M., Song, S-R., Ma, K-F., Hung, J-H., Wang, C.-Y., and Tsai, Y-B. 2006b., High magnetic susceptibility of fault gouge within Taiwan Chelungpu fault: Nondestructive continuous measurements of physical and chemical properties in fault rocks recovered from Hole B, TCDP, Geophysical Research letters, 33, L15303.

Hirono, T., Yokohama T., Hamada Y., Tanikawa W., Mishima T., Ikehara M., Famin V., Tanimizu M., Lin W., Soh W., and Song S.-R. 2007. A chemical kinetic approach to estimate dynamic shear stress during the 1999 Taiwan Chi-Chi earthquake, Geophysical Research Letters, 34, L19308.

Hirono, T., Fujimoto K., Yokoyama T., Hamada Y., Tanikawa W., Tadai O., Mishima T., Tanimizu M., Lin W., Soh W., and Song S. 2008. Clay mineral reactions caused byfrictional heating during an earthquake: An example from the Taiwan Chelungpu fault, Geophys. Res. Lett., 35, L16303.

Hueckel T. \& Pellegrini, R., 1991. Thermoplastic modelling of undrained failure of saturated clay due to heating. Soils and Foundations, 31 (3): 1-16.

Italiano, F., Martinelli, G. and Plescia P. 2008. $\mathrm{CO}_{2}$ degassing over seismic areas: The role of mechanochemical production at the study case of central Apennines, Pure Appl. Geophys. 165: 75-94.

Kanamori, H. \& Rivera, L. 2006. Energy partitioning during an earthquake. In R. Abercrombie et al. (eds.), Radiated Energy and the Physics of Faulting, Geophys. Monogr. Ser., vol. 170, AGU, Washington, D. C., 3-13.

Lachenbruch, A.H. 1980. Frictional heating, fluid pressure and the resistance to fault motion. J. Geophys. Res, 85: 60976112.

Lachenbruch, A.H., \& Sass J.H. 1980. Heat Flow and Energetics of the San Andreas Fault Zone, J. Geophys. Res, 85: 6185-6223.

Lee, T. C., \& Delaney, P. T., 1987. Frictional heating and pore pressure rise due to a fault slip, Geophys. J. R. Astron. Soc., 88(3): 569- 591.
Lewicki, J.L., \& Brantley S.L., 2000. $\mathrm{CO}_{2}$ degassing along the San Andreas fault, Parkfield, California, Geophysical Research Letters, 27 (1): 5-8.

Lewicki,J.L., Evans W.C., Hilley, G. E., Sorey, M. L., Rogie, J. D.and Brantley S. L., 2003. Shallow soil CO2 flow along the San Andreas and Calaveras Faults, California, Journal of Geophysical Research, 108, B4, 2187.

L'vov, B.V., 2002. Mechanism and kinetics of thermal decomposition of carbonates, Thermochimica Acta, 386: 1-16.

Milsch, H., Heinrich, W., and Dresen, G. 2003. Reactioninduced fluid flow in synthetic quartz-bearing marbles. Contrib Mineral Petrol. 146: 286-296.

Noda, H. E., Dunham M. and Rice J. R. 2009. Earthquake ruptures with thermal weakening and the operation of major faults at low overall stress levels, J. Geophys. Res, 14, B07302.

Otsuki, K., Monzawa N., and Nagase T. 2003. Fluidization and melting of fault gouge during seismic slip: Identification in the Nojima fault zone and implications for focal earthquake mechanisms. J. Geophys. Res., 108 B4.

Pizzino, L, Quattrochi, F.,Cinti, D., Galli, G., 2004. Fluid geochemistry along the Eliki and Aigion seismogenic segments Gulf of Corinth, Greece, C. R. Geoscience, 336(4-5): 367374.

Rice, J. R., 2005. Large scale localization: Thermal weakening of faults during seismic slip, in: Thematic Meeting on Instabilities, Bifurcations, Localization, 24- 25 February 2005, Institut Poincaré, Paris, France.

Rice, J.R. 2006. Heating and weakening of faults during earthquake slip, J. Geophys. Res., 111, B05311.

Rice, J. R., Dunham, E. M. and Noda, H. 2009. Thermo- and hydro-mechanical processes along faults during rapid slip. In H. Hatzor, J. Sulem \& I. Vardoulakis (eds), Meso-Scale Shear Physics in Earthquake and Landslide Mechanics CRC Press: 3-16.

Sato, T. \& Takahashi M., 1997. Geochemical changes in anomalously discharged groundwater in Awaji Island -after the 1995 Kobe earthquake. Chikyukagaku 31: 89-98.

Scholz, C. 2006. The strength of the San Andrea fault: a critical analysis. In R. Abercrombie et al. (eds.), Radiated Energy and the Physics of Faulting, Geophys. Monogr. Ser., vol. 170, AGU, Washington, D. C., 301-311.

Sulem, J., 2007. Stress orientation evaluated from strain localization analysis in Aigion fault, Tectonophysics, 442: 3-13.

Sulem, J., Vardoulakis, I., Ouffroukh, H., Boulon M., and Hans J. 2004. Experimental characterization of the thermo-poromechanical properties of the Aegion fault gouge, C. R. Geosciences, 336(4- 5): 455- 466.

Sulem, J., I. Vardoulakis, H. Ouffroukh, and V. Perdikatsis, "Thermo-poro-mechanical properties of the Aigion fault clayey gouge - application to the analysis of shear heating and fluid pressurization", Soils Found., 45(2), 2005, p.97108.

Sulem, J., Lazar, P. and Vardoulakis, I. 2007. Thermo-PoroMechanical Properties of Clayey Gouge and Application to Rapid Fault Shearing. Int. J. Num. Anal. Meth. Geomechanics, 31(3): 523-540.

Sulem, J. \& Famin, V. 2009 Thermal decomposition of carbonates in fault zones: slip-weakening and temperature-limiting effects, J. Geophys. Res., 114, B03309.

Sulem, J., Famin, V. and Noda H.E., 2009. A correction to "Thermal decomposition of carbonates in fault zones: slipweakening and temperature-limiting effects", J. Geophys. Res., 114, B06311,

Sultan, N., Delage, P. and Cui, Y.J., 2002. Temperature effects on the volume change behaviour of Boom clay. Engineering Geology, 64 (2-3): 135-145. 
Vardoulakis, I., 2002. Dynamic thermo-poro-mechanical analysis of catastrophic landslides, Géotechnique, 52(3): 157171.

Vardoulakis, I. \& Sulem, J., 1995. Bifurcation analysis in geomechanics. Blackie Academic and Professional.

Veveakis, E., Vardoulakis, I. and Di Toro, G. 2007. Thermoporomechanics of creeping landslides: The 1963 Vaiont slide, northern Italy, J. Geophys. Res., 112, F03026.

Voight, B. \& Faust C. 1982. Frictional heat and strength loss in some rapid landslides, Géotechnique, 32: 43-54.

Wibberley, C., \& Shimamoto, T., 2005. Earthquake slip weakening and asperities explained by thermal pressurization, Nature 426 (4): 689-692.

Wagner, W., \& Pruß, A., 2002. The IAPWS formulation 1995 for the thermodynamic properties of ordinary water substance for general and scientific use. J. Phys. Chem. Ref. Data 31: 387 - 535.

Wright, T.W., 2002. The physics and mathematics of adiabatic shear banding. Cambridge University Press. 